\title{
The Interactive Relationship between Sci-Tech Innovation and Economic Growth: An Empirical Study Based on China Macroeconomic Data
}

\author{
QiTong $\mathrm{Yu}^{1}$, WenYu Dong ${ }^{1}$ \\ ${ }^{1}$ Finance Department of International Business School, Jinan University, China \\ Correspondence: WenYu Dong, Finance Department of International Business School, Jinan University, China.
}

Received: April 7, 2018

doi:10.11114/aef.v5i3.3180
Accepted: April 20, $2018 \quad$ Available online: April 22, 2018

URL: https://doi.org/10.11114/aef.v5i3.3180

\begin{abstract}
In the past decades, China has embraced a rapid development in its economy. And the sci-tech innovation has also gained unprecedented prosperity during the period. The progress in sci-tech innovation has boosted larger output in multiple industries of China, and thus having great contributions to the dramatic improvement in China's economy. The studies on the relationship between sci-tech innovation and economic growth has long been existed, however, most of which only focus on the one-way research, namely the effects of sci-tech innovation on the economic growth. Based on this status quo, this paper innovates from the research method to focus on the interactive relationship between sci-tech innovation and economic growth, establishing a VAR model to analyze their immediate structural relationship and long-term dynamic relationship, and finds out that the effects of sci-tech innovation on economic growth are immediate positive, while those on sci-tech innovation achievements appear in the long run. In the last part, this paper puts forward policy suggestions on the maximization of sci-tech innovation and economic growth based on the results.
\end{abstract}

Keywords: sci-tech innovation, economic growth, interactive relationship, VAR

\section{Introduction}

Since the implementation of the Strategy of Developing the Country Through Science in 1995, sci-tech innovation has been a significant driving force for China's economic development and social progress, and has gradually become an important symbol and basic guarantee for liberating the productive forces and continuous development. On the other hand, the ever rising GDP in China has prompted the further prosperity of the sci-tech innovation. Thus the level of sci-tech innovation has become an important indicator for the measurement of the level of economic development.

Compared to those of the year of 1991, the R\&D internal expenses of the whole society had increased by about 98 times and the number of patents had increased by about 73 times in the year of 2015, indicating that both the sci-tech innovation investments and the sci-tech innovation achievements have gained significant improvement. And the GDP level had increased by about 30 times during this period.

The material base for scientific and technological researches and innovative activities is the sci-tech investment, which will eventually contribute to the continuous economic growth by promoting sci-tech innovation achievements. Only by strengthening the emphasis on sci-tech investment and increasing the proportion of sci-tech output in GDP can we continue to positively promote sci-tech innovation and economic development. Only by clarifying the action mechanism and the relationships between sci-tech investment, sci-tech innovation achievements and economic development, can we better formulate economic development strategies, give full play to the positive interaction between sci-tech innovation and economic development and maximize the contributions of technological investment and technological innovation in the economic growth. Therefore, the interaction mode and function relation between sci-tech innovation and economic growth must still be further studied.

Based on the realistic background and theoretical analysis above, this paper adopts the VAR model, using the China macroeconomic data between the year of 1991 and the year of 2015. And we conduct an empirical analysis about the spot structure and the long-term dynamics between sci-tech innovation and economic growth, going through the cointegration test, the Granger causality test, the impulse response analysis and the variance decomposition. Regarding to the following structure of the article, the second part is the literature review, the third part is the model establishment, the fourth part is the index selection and the empirical analysis, the final part is the conclusion and the suggestion. 


\section{Literature Review}

The first systematic study of economic growth was the classical economist Adam Smith (1776), who pointed out that the core content of economy develop is the increase of national wealth, and to increase national wealth we must follow two means, namely, the division of labor productivity and the accumulation of capital. Adam Smith has made numerous references to technical improvements in The Wealth of Nations, and has clearly pointed out the importance of improvements, namely technological inventions and technological improvements, for productivity progress (Adam Smith, 2003). The representative of the classical political economy, David Ricardo, had made a further study on economic growth based on Adam Smith's theory, and he perceived that technological progress "not only increases national wealth, but also increases future productivity" (David Ricardo, 1821).

With regard to the relationship between technological progress and economic growth, as early as 1957, Solow put forward perspective that "total output is from the three major aspects as labor input, capital investment and technological progress" in his book Technical Change and the Aggregate Production Function. He also separated technological progress as an exogenous variable from the production functions, and argues that the part of the increase in output that is not accounted for by production factors is technological progress.

After Solow, more and more people were aware of the impact of technological progress on economic growth and began to study the contributions of technological progress in the economic field (Robert M Solow, 1957). Romer proposed the endogenous economic growth model, introducing research and development departments into the study. His view was that technological progress is the endogenous impact of economic growth and technology is the result of purposeful activities (Romer \& P.M, 1990). The R\&D model established by Aghion and Howitt shows that technological innovation and technological progress can have an impact on the economic system, in which new innovations take the place of old innovations and innovation achievement would lead to economic growth and cyclical change (Aghion \& $\mathrm{P}$ \& Howitt $\mathrm{P}, 1992)$.

The study on the impact of sci-tech innovation on economic growth in China started late. Jianwei Zhang (2012) considered that technological innovation progress promotes element innovation through advanced production factors, and is highly integrated into the production process of economic activity and becomes the decisive factor of economic growth by changing the factor form and function of regional economic development. Ruizhi Pang and her fellows conducted an empirical study on the support effect of sci-tech innovation to China's provincial economic development and the optimal allocation of innovative resources from a systematic perspective. The research shows that the support effect of sci-tech innovation on economic development of China's provinces is generally low (Ruizhi Pang \& Yu Fan \& Yang Li, 2014). Through the analysis on the interaction between sci-tech innovation and economic development in China, Wu Yang and Yi Yang (2016) found that sci-tech innovation and economic development have a coupling and coordinated development relationship, and this cooperative development plays an important role in promoting economic output. Yongmin Shang and Gang Zeng (2017) believe that sci-tech innovation plays an active role in the transformation of regional economic development mode, which is characterized by the promotion of economic development level and the transformation of economic structure, and the overall transformation of China's regional economic development modes to innovation-driven.

By carding relevant literatures, we find that, although in the early studies some economists have regarded sci-tech innovation as an exogenous variable when studying its effects on economic growth, with the further deepening of research and the introduction of endogenous economic growth model, more and more scholars have reached a consensus: that is, the technological progress is the endogenous influence factor of economic growth. However, most of the literatures focus on the impact of sci-tech innovation on economic growth, ignoring the adverse effects of economic growth on sci-tech innovation and how technological innovation interacts with economic growth during the long cycle of sci-tech innovation from inputs to outputs to economic growth.

Based on the above analysis, this article establishes the VAR model, takes the sci-tech innovation as an endogenous variable, measures the level of sci-tech innovation from two aspects of investment and achievement and studies the spot structure and the long-term dynamics of sci-tech innovation and economic growth, in order to complement and perfect the related theoretical research.

\section{Methodology}

In the 1980s, Christopher A. Sims founded and developed a vector autoregressive (VAR) model that can solve the problem of variable identification in an empirical study. In the VAR model, each variable takes lag variables as explanatory variables to form a model system of multivariate simultaneous equations. VAR model can well reflect the dynamic effects and hysteretic characteristics of endogenous variables. There are some methods based on VAR model can be used to analyze the dynamic relationship between variables, including multivariate Granger causality test, 
impulse-response analysis, and variance decomposition. They can also describe and forecast the macroeconomic variables, having become important methods in economic policy analysis.

The VAR model also has its deficiencies. For example, the traditional VAR model is easily affected by the order of the variables, reducing the reliability of the analysis results. Despite the deficiencies, the easily understood process still makes VAR model a useful tool for macroeconomic analysis. In the meantime, model sensitivity can be analyzed iteratively in index order to avoid analysis discrepancies caused by variable order.

Based on the analysis of the relationship between sci-tech innovation and economic development, this paper establishes a quaternary VAR (n) model, regarding sci-tech innovation investment, sci-tech innovation achievement and economic growth as analysis variables. The specific expression is:

$$
Y_{\mathrm{t}}=\alpha+\sum_{i=1}^{p} \beta_{i} Y_{\mathrm{t}-\mathrm{i}}+\varepsilon_{\mathrm{t}}
$$

In the formula (1), $Y_{t}$ is an endogenous variable, $\beta_{i}$ is $a(n \times n)-$ dimension Coefficient matrix, $Y_{t-i}$ is the $i$-order lag vector of the column vector $Y_{t}$, and the $\varepsilon_{t}$ is the random perturbation term, which satisfies the classical hypothesis of 0 mean value, same distribution and independent variable.

\section{Empirical Studies}

\subsection{Variable Selection and Data Source}

The data in this paper comes from the China Statistical Yearbook Science and Technology and the China Statistical Yearbook.

In the 20th century, China's economy and sci-tech innovation development were still at a low level stage. However, in the recent decades, they had experienced a dramatic ascension, especially after the implementation of the Strategy of Developing the Country Through Science in 1995. So data during this period is meaningful for conducting a research on the relationship between sci-tech innovation and economic growth.

The comprehensive level of sci-tech innovation can be reflected by both sci-tech innovation inputs and sci-tech innovation achievements. This paper chooses the R\&D internal expenses of the whole society to represent the sci-tech innovation investments, and chooses the number of patents to represent the sci-tech innovation achievements. And economic growth is measured by GDP. In order to eliminate the effect of variance, the selected indexes are processed by logarithm.

\subsection{Vector Autoregressive Model}

The premise of the VAR model is that each variable is stationary or of the same order, so it is necessary to test the stability of the variables before the model is established. And to ensure the validity of the empirical analysis results, we need to test the model after the model is established.

\subsubsection{Unit Root Test}

This paper uses ADF method to test the unit root of sci-tech innovation investment (LNRD), sci-tech innovation achievement (LNPA) and economic growth (LNGDP), to determine whether there are intercept terms and trend items according to the sequence diagram of each variable, and to determine the lag order according to AIC and SC information criterion. The result is shown below:

Table 1. ADF test results ( At 5\% significance level)

\begin{tabular}{llll}
\hline variable & ADF statistics & P-value & Stationarity results \\
\hline LNRD & -1.154161 & 0.6766 & Non-stationary \\
LNPA & 0.974962 & 0.9948 & Non-stationary \\
LNGDP & -0.320932 & 0.9053 & Non-stationary \\
DLNRD & -5.028827 & 0.0005 & stationary \\
DLNPA & -3.622031 & 0.0134 & stationary \\
DLNGDP & -4.120528 & 0.0051 & stationary \\
\hline
\end{tabular}

Table 1 show that at the significance level of 5\%, LNRD, LNPA and LNGDP are all non-stationary series. After first-order differencing, the three series become stationary in 95\% confidence intervals, and all variables are integrated of order one.

\subsubsection{Lag Selection}

According to the requests of the research, a three-dimensional vector autoregressive model based on LNRD, LNPA, and LNGDP variables was constructed. The lag length criterion was used to determine the lag order of the model. The results are shown below: 
Table 2. Determination of lag order

\begin{tabular}{lllllll}
\hline Lag & LogL & LR & FPE & AIC & SC & HQ \\
\hline 0 & 9.5381 & NA & 0.0001 & -0.5944 & -0.4456 & -0.5593 \\
1 & 106.6222 & 158.8649 & $3.73 \mathrm{e}-08$ & -8.6020 & $-8.0069^{*}$ & -8.4618 \\
2 & 119.6498 & $17.7649^{*}$ & $2.74 \mathrm{e}-0 *$ & $-8.9682^{*}$ & -7.9267 & $-8.7228^{*}$ \\
3 & 122.9356 & 3.5845 & $5.33 \mathrm{e}-08$ & -8.4487 & -6.9609 & -8.0982 \\
\hline
\end{tabular}

As are shown in table 2 , four of the five test indicators determine that the lag order 2 is the longest delayed order, and a vector autoregressive model with a lag order 2 (VAR (2)) is constructed according to the majority principle.

\subsubsection{The Stationary Test of VAR System}

In order to determine the validity of the impulse response analysis and the results of variance decomposition, we need to determine the stationarity of the VAR (2) model before the impulse response analysis. The test is conducted on the stationarity of the VAR (2) model. The result is shown in Figure 1: All the eigenvalues fall in the unit circle, so the VAR (2) model is stationary.

\section{Inverse Roots of AR Characteristic Polynomial}

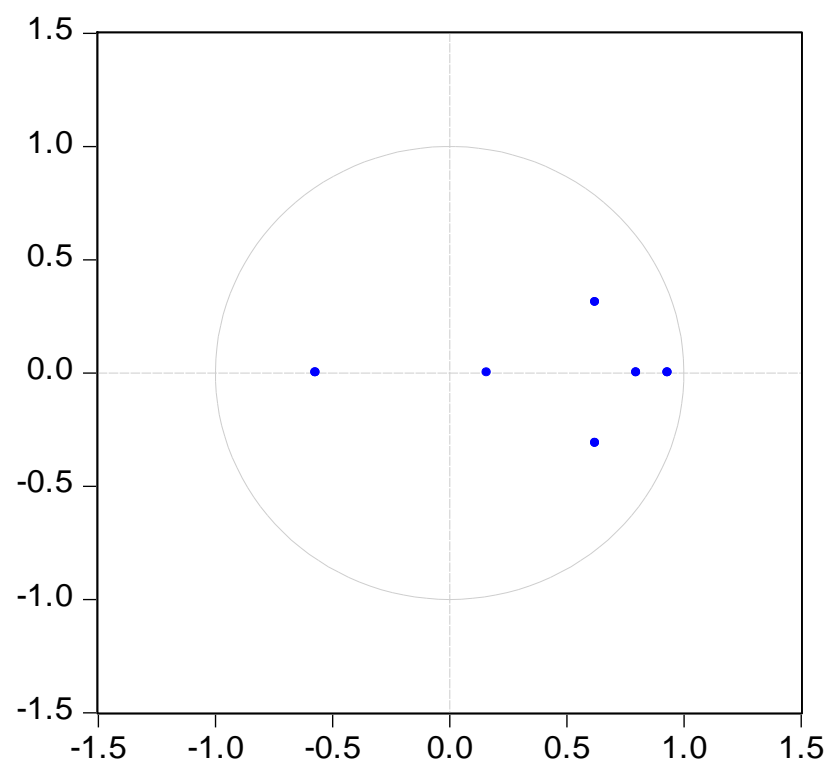

Figure 1. Result of VAR system stationarity test

\subsection{Granger Causality Test}

In order to determine whether there is a statistically causal relationship between the variables, after establishing the model of VAR (2), further testing of the three variables is needed, and the following results are obtained at the significance level of 5\%:

Table 3. Result of model variables Granger causality test (at 5\% significance level)

\begin{tabular}{ccc}
\hline Original hypothesis & P-value & Result \\
\hline LNRD is not the Granger cause of LNPA & 0.0052 & Deny \\
LNRD is not the Granger cause of LNGDP & 0.0397 & Deny \\
LNPA is not the Granger cause of LNRD & 0.0135 & Deny \\
LNPA is not the Granger cause of LNGDP & 0.7017 & Accept \\
LNGDP is not the Granger cause of LNRD & 0.0025 & Deny \\
LNGDP is not the Granger cause of LNPA & 0.2082 & Accept \\
\hline
\end{tabular}

According to the result of the Granger Causality Test, the influences between variables can be described as:

$$
\text { LNPA } \leftrightarrow \text { LNRD } \leftrightarrow \text { LNGDP }
$$

The Granger Causality Test conveys three important messages to us. First is that the level of the sci-tech innovation investment would directly affect the economic development, and that the growth of the national wealth would in turn promote investment into sci-tech innovation. Secondly, there exists a bidirectional relationship between sci-tech innovation investment and sci-tech innovation achievement. Thirdly, however, the sci-tech innovation achievement is not the Granger cause of economic growth, which means that the direct link between the sci-tech innovation achievement and the economic development was missing during the period. 


\subsection{Impulse Response Analysis}

Impulse response refers to the impact by the random error term of a variable on all endogenous variables in the current period and subsequent periods, and describes how the influence of the error term is passed to each variable, and how the time change trend of each endogenous variable is impacted. To be consistent with the sample interval, this paper sets the lag period as 25 years, the result of the impact of the variable is as shown in Figure 2: (the real line represents the pulse response function, and the dotted line indicates a deviation zone of positive and negative twice times deviation from the standard deviation)

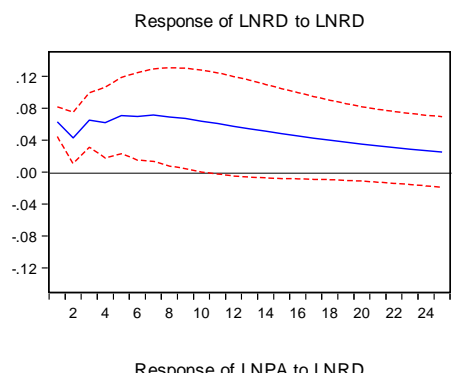

Response to Cholesky One S.D. Innovations?2 S.E.
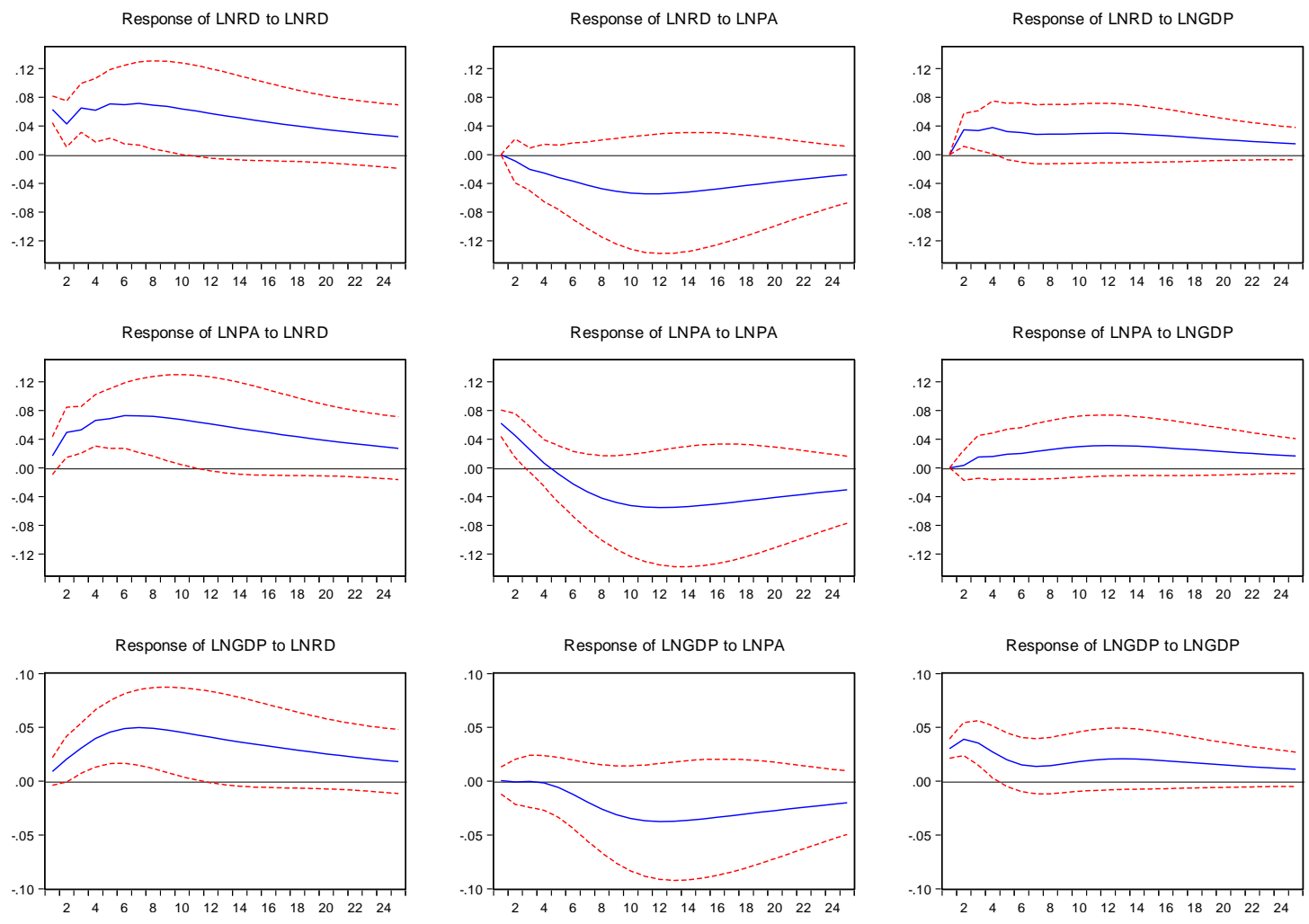

Figure 2. Impulse Response Analysis Results

(1) As is shown in the first line of Figure 2 (the second graph), when giving the sci-tech innovation investment a shock in this period, there will be a reverse effect on the steady growth of sci-tech innovation achievements. The reverse effect reached the peak in the 11th year, and then gradually weakened after the 11th year, it is because that the investments of innovative resources need to go through the project construction, talent introduction, scientific research and development, such a series of long process to produce economic benefits and to help enterprises produce competitive new products. So, the positive effect of the sci-tech innovation investment on the sci-tech innovation achievement only appears in the long term. On the other hand, it (the third graph) also shows that the shock on sci-tech innovation achievement would yield an immediate positive effect on economic growth. The effect is gradually increasing during the first 1-2-year, steady in 2-4 year and gradually weakening after the 4th year. In general, sci-tech innovation investment has a positive effect on economic growth.

(2) The second line of Figure 2 (the first graph) shows that when giving a shock to the sci-tech innovation achievement in this period, there is a positive effect on sci-tech innovation investment. The effect is gradually becoming stronger in 1-6 year and then gradually becoming weaker after the 6th year, indicating that the sci-tech innovation achievement has a long-term reverse effect on the sci-tech innovation investment. And according to the third graph of the second line, the shock on the sci-tech innovation achievement leads to an immediate and steadily growing positive effect on the economic growth, and the long-term positive effect is more obvious than the short term, which shows that the sci-tech innovation achievement will gradually merge with the economic and social development with the passage of time, and have a long-term and stable effect on economic growth.

(3) According to the third line of Figure 3 (the first graph), giving the economic growth a shock in this period, there is a positive effect on sci-tech innovation investment. The effect is gradually becoming stronger at the beginning and then gradually becoming weaker after the 8th year. In general, the economic growth has a positive effect on sci-tech 
innovation investment, indicating that as the society and economy develop, the material resources used for research and development are gradually increasing, and an interactive effect are existing between the economic growth and the sci-tech innovation. Finally, this would lead to the phenomenon of "economic growth promotes sci-tech innovation investment and sci-tech innovation investment in return accelerates economic development". While the second graph shows that giving the economic growth a shock will result in the 12-year continuous growing of a reverse effect on the sci-tech innovation achievement. We notice that giving the sci-tech innovation investment could produce similar effect on the sci-tech innovation achievement (the second graph in the first line). However, sci-tech innovation investment could yield an immediate effect on the economic growth (the first graph in the third line), showing that the efficiency loss appears in the link from the technology input to the output. It is because the chain between input and output is rather long, the middle input is too much, and the probability of information loss and distortion in each link is rather high, causing a reduction in the efficiency of innovation output.

\subsection{Variance Decomposition Analysis}

As the impulse response analysis only describes the response of the error term of each variable to the impact of other endogenous variables, in order to analyze the relative contribution of each structure to the impact of endogenous variables, this paper analyzes the variance of LNRD, LNPA and LNGDP based on the VAR (2) model, and selects the 25 period as the lag period. The results of the decomposition are shown in Figure 3:
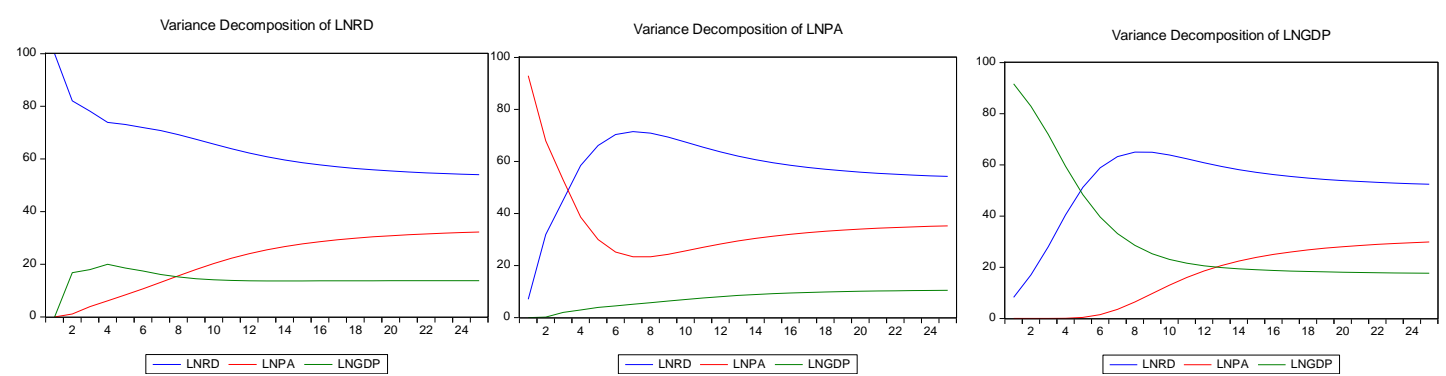

Figure 3. Variance Decomposition of Predictive Error

According to the first graph from Figure 3, the sci-tech innovation investment shows a strong "self-realization" function and the biggest contribution to its fluctuation is itself. 50\%-100\% of the variation is explained by the sci-tech innovation investment itself, $0-32 \%$ of the variation is explained by the result of sci-tech innovation and $0-20 \%$ of the variation is explained by economic growth. The second graph tells us that during a period of 1-3 years, 53\%-93\% of the variation of the sci-tech innovation achievement is explained by itself. After the 3rd year, the biggest contribution to the variation of the sci-tech innovation achievement is the sci-tech innovation investment, explaining 53\%-71\% of the variation. It can be seen from the third graph that the economic growth shows a strong "self-realization" function as sci-tech innovation achievement do in the short term. In 1-5 years, 51\%-92\% of the variation of economic growth is explained by itself, and after the 5th year the variation is mainly explained by sci-tech innovation investment, showing that the sci-tech input has made significant contributions to sci-tech output and economic growth.

\section{Conclusions and Suggestions}

\subsection{Conclusion}

This paper uses a VAR model to analyze the interactive relationship between sci-tech innovation and economic growth. The sci-tech innovation is divided into two processes, the sci-tech innovation investment and the sci-tech innovation achievement, in order to better clarify the conduction mechanism of influence. And we come to conclusions that:

(1) There exists an important interactive relationship between the sci-tech innovation investment and the economic growth. Since the Strategy of Developing the Country Through Science in 1995, China has poured significant amount of investment into the sci-tech industry, which is proved to be a crucial factor in driving economic development. And as economy grows, more investment would be poured into the sci-tech innovation.

(2) While having an immediate positive effect on economic growth, sci-tech innovation investment has a hysteresis effect on sci-tech innovation achievement. It shows that the conversion from the sci-tech innovation investment to the sci-tech innovation achievement takes a rather long period.

(3) The Granger test results show us that sci-tech innovation achievement is not the cause of economic growth, which means that the linkage between them is not apparent enough. This can be explained by the second conclusion that the conversion from inputs to outputs is lack of efficiency.

\subsection{Suggestion}

Based on the above analysis and empirical results, this paper gives three main suggestions: 
(1) Based on the fact that sci-tech innovation investment supports the sci-tech innovation achievement, government should continue to increase sci-tech innovation investment, guide the direction of sci-tech innovation investment, standardize the management mode of sci-tech innovation investment and make rational investment policy, in order to optimize the efficiency of the conversion between sci-tech inputs and sci-tech outputs.

(2) As to strengthen the support by sci-tech innovation achievements on economic development, government should further adjust the economic industrial structure, guarantee and improve the transformation ability of sci-tech innovation investment by omni-channel method, and pay attention to adjust the organization mode of sci-tech planning.

(3) According to the mutual promotion between economic growth and sci-tech innovation investment, government should establish long-term mechanism of sci-tech innovation investment and sci-tech innovation achievement with a premise of the stability rapid growth of economy, highlight and protect the effects of sci-tech factors in economic growth, thus promoting economic development.

\section{References}

Adam, S. (2003). The Wealth of Nations. Bantam: Bantam Classics.

Aghion, P., \& Howitt, P. (1992). A Model of Growth through Greative Destruction. Econometrica, (60), 323-351. https://doi.org/10.2307/2951599

Boskin, M, J., \& Lau, L. J. (2000). Generalized Solow-Neutral Technical Progress and Postwar Economic Growth. National Bureau of Economic Research(NBER), (12). https://doi.org/10.3386/w8023

David, R. (1821). On the Principles of Political Economy and Taxation. London G. Woodfall Printer.

Jianwei, Z. (2012). The effect of technical innovation on economic transition: An empirical analysis of China. Shanghai: Doctoral Dissertation of East China Normal University.

Robert, M. S. (1957). Technical Change and the Aggregate Production Function. Reviews of Economic and Statistics, (3), 312-320.

Romer, P. M. (1990). Increasing Returns and Long-Run Growth. Journal of Political Economy, (98), S71-S102. https://doi.org/10.1086/261725

Ruizhi, P., \& Yu, F., \& Yang, L. (2014). Does China's scientific and technological innovation support economic development?. Quantitative economic and technological economics research, (10), 37-52.

Wu, Y., \& Yi, Y. (2016). Coupled coordination degree model of scientific and technological innovation and economic development in China. China Science and Technology Forum, (3), 30-35.

Yonggang, S., \& Gang, Z. (2017). Scientific and technological innovation promotes the transformation of regional economic development mode: function and mechanism. Geographical Research, 36(12), 2279-2290.

\section{Copyrights}

Copyright for this article is retained by the author(s), with first publication rights granted to the journal.

This is an open-access article distributed under the terms and conditions of the Creative Commons Attribution license which permits unrestricted use, distribution, and reproduction in any medium, provided the original work is properly cited. 